\title{
The Use of Cross-Sectional and Longitudinal Weights in Korean Health Panel Survey
}

\author{
Kyu Seong Kim* \\ Department of Statistics, University of Seoul, South Korea
}

*Corresponding author: Kyu Seong Kim, Professor of Department of Statistics, The University of Seoul, South Korea.

To Cite This Article: Kyu Seong Kim, The Use of Cross-Sectional and Longitudinal Weights in Korean Health Panel Survey. Am J Biomed Sci \& Res 2020 - 10(4). AJBSR.MS.ID.001539. DOI: 10.34297/AJBSR.2020.10.001539.

Received: 眥 September 28, 2020; Published: 眥 October 15, 2020

\section{Introduction}

In household panel surveys, the same households and individuals are interviewed at multiple time points and then information is obtained from them. Panel studies have considerable analytical advantages over one-time surveys such as analysis of gross change, analysis of unit-level change, analysis of time related characteristics of events and identifying causality [1,2]. However, panel surveys often suffer from a high degree of panel attrition between waves, where panel attrition means the continued loss of respondents from the original sample due to mortality, migration between waves and survey non-response [2,3].

\section{The Korean Health Panel Survey}

The Korean Health Panel (KHP) survey is a household panel survey conducted by the Korean Institute for Health and Social Affairs. The KHP survey was designed to examine medical service use, out-of-pocket healthcare payments and uninsured medical services. The KHP survey has provided not only information on health care utilization and health care expenditure among household and individuals, but also various factors such as socio-

Table 1: The evolution of household and individual samples in KHP survey.

\begin{tabular}{|c|c|c|c|c|}
\hline Year & Household & Individual & Year & Household \\
\hline 2008 & 7,009 & 21,283 & 2014 & 19,219 \\
\hline 2009 & 6,314 & 19,153 & 2015 & 6,607 \\
\hline 2010 & 5,956 & 17,885 & 2016 & 6,130 \\
\hline 2011 & 5,741 & 17,035 & 2017 & 6,408 \\
\hline 2012 & 5,434 & 15,872 & 2018 & 6,379 \\
\hline 2013 & 5,200 & & & \\
\hline
\end{tabular}

Note: Source: Korea Health Panel site (www.khp.re.kr) 


\section{Cross Sectional and Longitudinal Weights}

Many panel surveys provide two kinds of weights, crosssectional weights and longitudinal weights to data users. Basic distinction between the two weights comes from the different populations to be represented. There are $2^{\mathrm{t}}-1$ possible combinations of populations that can be represented by a t-wave panel survey. Among them $t$ are cross-sectional populations and $\left(2^{t}-1-t\right)$ are longitudinal populations [2]. Annual cross-sectional target population changes every year due to birth, death and immigrants. For this reason, the cross-sectional sample for a given year is composed of all longitudinal persons and cohabitants living with longitudinal persons on the corresponding reference year [810]. Survey weights are attached to the sample units and used to estimate population parameters. The cross-sectional weights are useful for Cross-sectional populations and the longitudinal weights are useful for longitudinal populations.

In KHP survey, both cross-sectional weights and longitudinal weights has been constructed and provided to data users from the first year of 2008. The following Table 2 shows the estimated individual's medical expenditures from cross-sectional and longitudinal respondents on the original panel each year, where cross-sectional weights and longitudinal weights are used to calculate the estimates respectively (Table 2).

Table 2: Estimated individual's medical expenditures in KHP survey (US \$).

\begin{tabular}{|c|c|c|c|c|}
\hline \multirow{2}{*}{ Year } & \multicolumn{2}{|c|}{ Cross-Sectional Sample of Individuals } & \multicolumn{2}{c|}{ longitudinal Sample of Individuals } \\
\cline { 2 - 5 } & Size & Mean & Size & 302.46 \\
\hline 2008 & 21,250 & 302.46 & 21,250 & 322.89 \\
\hline 2009 & 19,127 & 321.79 & 18,852 & 347.63 \\
\hline 2010 & 17,872 & 347.88 & 17,392 & 385.65 \\
\hline 2011 & 17,028 & 382.53 & 16,413 & 411.21 \\
\hline 2012 & 15,858 & 411.87 & 14,062 & 437.02 \\
\hline 2013 & 14,838 & 430.25 & 13,128 & 428.19 \\
\hline 2014 & 13,972 & 430.44 & 12,533 & 444.67 \\
\hline 2015 & 13,257 & 443.53 & 12,005 & 492.5 \\
\hline 2016 & 12,760 & 489.49 & 11,603 & 501.49 \\
\hline 2017 & 12,655 & 505.54 & 11,388 & 541.96 \\
\hline
\end{tabular}

From the table we found four meaningful results. First, both the number of longitudinal and cross-sectional respondents is decreasing due to panel attrition, which is the same as the case of households. Second, cross-sectional sample size is greater than longitudinal sample size because of cohabitant in the sample households. For an example of 2018 year, the longitudinal sample size went down to 11,388 individuals, which is at most $90.9 \%$ of the cross-sectional sample. Third, the individual's medical expenditures are increasing in both samples, which can be explained by aging effect of panel members and economic growth effect. Finally, two estimated medical expenditures are similar and not significant in each year. It may be due to the shortage of cohabitant sample.

\section{Summary}

In this review, I addressed the Korean Health Panel survey, which is a household panel survey, started in 2008. The survey has provided some useful information on health care utilization and health care expenditure as well. Like other panel surveys, the KHP survey has suffered from panel attrition. To support the crosssectional representativeness of the survey due to panel attrition, a top-up sample was added in 2014. Both cross-sectional weights and longitudinal weights has been constructed and used to estimate the cross-sectional population parameter as well as longitudinal population parameter each year.

\section{References}

1. Hsiao C (2014) Analysis of panel data, 3rd Edition Cambridge.

2. Lynn P (2009) Methodology of longitudinal surveys. Wiley.

3. Lee U (2003) Panel attrition in survey data: a literature review. CSSR Working paper no.41.

4. Korea Institute for Health and Social Affairs (2019) A report on the Korea Health Panel Survey of 2017. KIHSA research report 43-01.

5. Korea Institute for Health and Social Affairs (2019) A study of strategies for the 2nd Korea Health Panel Project. KIHSA research report 43-02.

6. Korea Institute for Health and Social Affairs (2008) A report on the survey process of the Korean Health Panel Survey of 2008. KIHSA research report 22-2.

7. Korea Institute for Health and Social Affairs (2016) A study of strategies for improving the Korea Health Panel. KIHSA research report 31-2.

8. LaRoche S (2007) Longitudinal and cross-sectional weighting of the Survey of Labor and Income Dynamics. Statistics Canada research report 75F0002M-00004.

9. Latouche M, Dufour J, Merkouris T (2000) Cross-sectional weighting: combining two or more panels. Statistics Canada research report.

10. Naud J F (2004) Combined-panel longitudinal weighting Survey of Labor and Income Dynamics. Statistics Canada research paper. 